\title{
Bal Üretim Ormanları İçin Potansiyel Bitki Tüirleri: Isparta Keçiborlu Güneykent Bal Üretim Ormanı Örneği
}

Süleyman Yıldız*, Hüseyin Fakir¹

Özet: Bu çalışmada, Güneykent Bal Üretim Ormanının mevcut flora çalışması yapılarak, arıcılık için elverişli nektar ve polenli bitki yoğunluğu belirlenmiştir. Ayrıca Güneykent Bal Üretim Ormanında yıl içerisinde nektar akımı dönemini uzatmak amacıyla bitkilerin çiçeklenme dönemi dikkate alınarak yörenin orijinine uygun türlerle dikimler yapılmıştır. Tohum ve/veya fidan kullanılırken yetişme ortamına uygun türler ve orijininden olmalarına özen gösterilmiştir. Bal ormanlarındaki ağaçların azami çiçek tutmaları büyük önem arz ettiğinden, dikimlerdeki aralık mesafesine dikkat edilmiştir. Çalışma alanında birbirini takip ederek çiçek açabilen ağaç ve orman altı bitki örtüsünü bir arada bulundurulması sağlanmıştır. Bal ormanı projelerinde, hedeflerin gerçekleştirilebilmesi için özellikle çiçeklenme periyodunun uzun olmasını sağlayan ağaç, çalı ve otsu türlerin olmasına özen gösterilmiştir. Araştırma sonucunda arılar tarafından en fazla ziyaret edilen bitki grubunu 9 takson ile Rosaceae familyası oluştururken, Fabaceae familyas 5 takson ile ikinci sırada, Lamiaceae familyası ise 5 takson ile üçüncü sırada yer almıştır. Bununla birlikte arıcılık açısından son derece önemli olan çiçeklenme dönemleri dikkate alındığında, Nisan, Mayıs, Haziran ve Temmuz aylarının çiçeklenmenin en yoğun olduğu dönem olduğu saptanmıştır.

Anahtar Kelimeler: Bal üretim ormanı, arıcılık, tıbbi-aromatik bitki taksonları, çiçeklenme zamanı, Isparta-Keçiborlu

\section{Potential Plant Species for Honey Production Forests: Isparta Keçiborlu Güineykent Honey Production Forest Case}

\begin{abstract}
In this study, the density of nectar and pollen plants suitable for beekeeping was determined by conducting floral studies. In addition to this, plantations were made by using suitable species for the origin of the region, in order to extend nectar flowing period. It was taken into consideration to using suitable seed/seedlings for the habitat and their origin. Since the maximum flowering of the trees in the honey forests is of great importance, attention has been paid to the spacing in the plantings. In the study area, it was ensured that the trees and sub-vegetation which could bloom could follow together. In order to realize the objectives of honey forest projects, especially trees, bush and herbaceous species that provide a long period of flowering were taken care. The most visited group of plants by bees was the Rosaceae family with 9 taxa, the Fabaceae family ranked second with 5 taxa, and the Lamiaceae family ranked third with 5 taxa. However, considering the flowering periods which are very important in terms of beekeeping, April, May, June and July were found as the most intense flowering period.
\end{abstract}

Keywords: Honey production forest, beekeeping, medicinal-aromatic plant taxa, flowering time, IspartaKeçiborlu

${ }^{1}$ Isparta Uygulamalı Bilimler Üniversitesi, Orman Fakültesi, Orman Mühendisliği Bölümü, Isparta, Türkiye

*Corresponding author (İletişim yazarı) syildizemir@gmail.com
Citation (Atıf): Yıldız, S., Fakir H. (2019). Bal Üretim Ormanları İçin Potansiyel Bitki Türleri: Isparta Keçiborlu Güneykent Bal Üretim Ormanı Örneği Bilge International Journal of Science and Technology Research, 3 (2): 213-222. 


\section{Giriş}

Arıcılık günümüzde gelişmiş ve gelişmekte olan ülkelerde önem verilen bir hayvancılık dalıdır. Arıcılık faaliyeti, toprağa ihtiyaç duyulmayan, az sermaye ve düşük maliyetle üretim yapılabilen kısa süre içerisinde gelir getiren, tarımsal bir uğraştır (Parkalay vd, 2008). Dünyada yaklaşık 74 milyon arı kovanı vardır ve bunlardan yaklaşık 1.4 milyon ton bal üretimi sağlanmaktadır. Çin, 7.4 milyon arı kovanına sahip olması sebebi ile en çok kovanı olan ve bal üreten bir ülkedir. Çin'den sonra Türkiye, Arjantin, Ukrayna ve ABD ile devam etmektedir (Günaydın, 2007). Türkiye kovan varlığı bakımından dünyada ikinci sıradadır lakin kovan başına ortalama $16 \mathrm{~kg}$ civarında olup dünya ortalaması olan 20 kg'ın altındadır (Özcan, 2011).

Arıcılık, arı ürünleri üretiminin çeşitliliği nedeniyle, dünyada gelişmiş ülkelerde ve gelişmekte olan ülkelerde hızlı gelişme gösteren bir aktivitedir. Balın ve diğer arı ürünlerinin insan sağlığına olan katkılarının son yıllarda daha iyi bilinmesi, gıda, tedavi ve kozmetik alanlarında kullanımının yaygınlaşması arıcılığı ve arı ürünlerinin üretilmesini karlılığı arttırdığı için bu sektörü ön plana taşımıştır (Yaşar vd., 2012). Arıcılık faaliyeti, Avrupa'da genellikle geleneksel bir uğraş, İspanya, Polonya, Macaristan, Yunanistan ve Türkiye gibi ülkelerde gelir getirici bir araç, Uzak doğu, Orta ve Güney Amerika ve Afrika ülkelerinde önemli bir dış gelir kaynağı, $\mathrm{ABD}$, Kanada, Japonya gibi ülkelerde ise bitkisel tozlaşmaya katkı sağlayan bir faaliyet olarak görülmektedir (Vural, 2008).

Türkiye zengin bitki varlığı, uygun ekolojisi açısından arıcılıkta önemli bir potansiyeli vardır. Ancak sektör bu doğal kaynak zenginliğinden yeterince yararlanamamaktadır. Türkiye'nin sırasıyla Ege, Karadeniz ve Akdeniz Bölgeleri gerek kovan varlı̆̆ı, üretim payı bakımından arıcılık için en önemli bölgelerimizdir. Türkiye bal üretiminin yaklaşık yarısı bu üç bölgemizde gerçekleşmektedir. 2015 yılı itibariyle Türkiye'nin toplam bal üretimi 107665 ton, balmumu üretimi ise 4750 ton dolayındadır. Koloni başına ortalama bal verimi $14-18 \mathrm{~kg}$ dolayında olup, bu değer arıcılığı gelişmiş ülkelerdeki verimin üçte biri kadardır. 2002-2015 döneminde bal üretiminde $\% 69$ oranında bir artış gerçekleşmiştir (TUIK, 2015).
Bal üretim ormanlarının kurulması Ülkemizin zengin florası, uygun ekolojisi ve koloni varlığı açısından arıcılıkta büyük bir potansiyele sahip olduğunu göstermektedir. Ancak bu üretim faaliyetinden tam olarak yararlanılamamaktadır. $\mathrm{Bu}$ avantajların bilinçli kullanımı ile bir gıda olan bal üretimi daha fazla gerçekleşmiş olacak az masrafla yapılabilecek bir üretim kolu olduğundan istihdama ve ülke ekonomisine katkı sağlanacaktır (Parlakay vd, 2008).

Türkiye genelinde 2015 y1l sonu itibari ile Orman Genel Müdürlüğü bünyesinde 234 adet bal üretim ormanı kurulmuștur. Bunlardan 2010 'da 4 adet, 2011'de 3 adet, 2012'de 1 adet, 2013'de 2 adet, 2014 'de 2 adet, 2015'de 1 adet olmak üzere 13 tanesi Isparta Orman Bölge Müdürlüğü’ne bağl1 bal üretim ormanlarıdır (Çizelge 1.2).

Arıcılık sektörünün Orman Genel Müdürlüğü tarafindan desteklenmesi ve Bal Ormanı Eylem Planı (2013-2017) kapsamında, biyolojik çeşitliliğinin korunması, erozyonun önlenmesi, sağlıklı ve kaliteli bal üretiminin en üst seviyelere erişebilmesi, sürdürülebilir şekilde halkın ormandan faydalanmasının sağlanması ve halkın ekonomik açıdan kalkındırılması için Türkiye ormanlarında tesis edilen Bal Üretim Ormanları içerisinde bulunan Keçiborlu Orman İşletme Şefliği Güneykent Bal Üretim ormanında mevcut kullanılan bitki taksonları tespit edilerek, arıcılık için elverişli nektar ve polenli bitki yoğunluğu belirlenmiş, doğaya yakın bir ormancılık içerisinde ne kadar ekim/dikim ihtiyacı olduğu tespit edilmiştir. Yıl içerisinde nektar akımı dönemini uzatmak amacıyla bitkilerin çiçeklenme dönemi dikkate alınarak yörenin orjinine uygun ilave hangi türlerle takviye edileceği ortaya konulmuştur. 
Çizelge 1.2. Isparta Orman Bölge Müdürlüğünde Bulunan Bal Üretim Ormanları (Anonim, 2017)

\begin{tabular}{|c|c|c|c|c|c|c|c|}
\hline $\begin{array}{l}\text { S. } \\
\text { No }\end{array}$ & $\begin{array}{l}\text { Bölge } \\
\text { Müdürrlüğ̈̈ }\end{array}$ & $\begin{array}{l}\text { İşletme } \\
\text { Müdürlüğüu }\end{array}$ & $\begin{array}{l}\text { Alanı } \\
\text { (Ha) }\end{array}$ & İli & Proje Adı & $\begin{array}{l}\text { Tesis } \\
\text { Yılı }\end{array}$ & $\begin{array}{l}\text { Proje } \\
\text { Maliyeti } \\
\text { (TL) }\end{array}$ \\
\hline 110 & Isparta & Eğirdir & 10,0 & Isparta & $\begin{array}{l}\text { Rehabilitasyon } \\
\text { Çalıșması }\end{array}$ & 2011 & $10.000,00$ \\
\hline 111 & Isparta & Eğirdir & 7,2 & Isparta & $\begin{array}{l}\text { Rehabilitasyon } \\
\text { Calıșması }\end{array}$ & 2010 & $7.000,00$ \\
\hline 112 & Isparta & Sütçüler & 57,8 & Isparta & $\begin{array}{l}\text { Rehabilitasyon } \\
\text { Çalışması }\end{array}$ & 2010 & $86.700,00$ \\
\hline 113 & Isparta & Burdur & 10,0 & Burdur & $\begin{array}{l}\text { Rehabilitasyon } \\
\text { Çalışması }\end{array}$ & 2010 & $2.500,00$ \\
\hline 114 & Isparta & Bucak & 50,0 & Burdur & $\begin{array}{l}\text { Rehabilitasyon } \\
\text { Çalıșması }\end{array}$ & 2010 & $75.000,00$ \\
\hline 115 & Isparta & Bucak & 54,3 & Burdur & $\begin{array}{ll}\text { Dikenli } & \text { Bal } \\
\text { Ormanı } & \end{array}$ & 2014 & $22.099,85$ \\
\hline 116 & Isparta & Isparta & 138,4 & Isparta & $\begin{array}{l}\text { Güneykent Bal } \\
\text { Ormanı }\end{array}$ & 2013 & $80.253,37$ \\
\hline 117 & Isparta & Isparta & 95,0 & Isparta & $\begin{array}{ll}\text { Senir } & \text { Bal } \\
\text { Ormanı } & \end{array}$ & 2015 & $76.772,19$ \\
\hline 118 & Isparta & Gölhisar & 24,6 & Isparta & $\begin{array}{l}\text { Beyköy } \quad \text { Bal } \\
\text { Ormanı }\end{array}$ & 2013 & $\begin{array}{l}154.081,8 \\
4\end{array}$ \\
\hline 119 & Isparta & Sütçüler & 49,2 & Isparta & $\begin{array}{ll}\text { Sütçüler } & \text { Bal } \\
\text { Ormanı } & \end{array}$ & 2014 & $45.003,02$ \\
\hline 120 & Isparta & Dinar & 87,0 & Afyon & $\begin{array}{ll}\text { Gökçek } & \text { Bal } \\
\text { Ormanı }\end{array}$ & 2011 & $\begin{array}{l}261.000,0 \\
0\end{array}$ \\
\hline 121 & Isparta & Dinar & 33,0 & Afyon & $\begin{array}{ll}\text { Yüreğil } & \text { Bal } \\
\text { Ormanıo } & \end{array}$ & 2011 & $99.000,00$ \\
\hline 122 & Isparta & Dinar & 107,0 & Afyon & $\begin{array}{ll}\text { Evciler } & \text { Bal } \\
\text { Ormanı } & \\
\end{array}$ & 2012 & $\begin{array}{l}390.626,3 \\
0\end{array}$ \\
\hline
\end{tabular}

\section{Materyal}

\section{1. Çalışma sahası}

Araştırma 2015-2016 yıllarında, Isparta İli Gönen İlçesi Güneykent Beldesi yöresinde Güneykent Bal Üretim Ormanında yapılmıştır. Çalışma alanının denizden yüksekliği $990-1250 \mathrm{~m}$. arasında değişmekte olup, UTM WGS 8436. Zon' a göre 4204065 - 4204066 m. kuzey enlemleri ile 270134 - 269953m. doğu boylamları arasında yer almaktadır. Toplam çalışma alanı 138,50 ha'dır. Çalışma alanının coğrafi konumu Şekil 1'de verilmiştir (Şekil 1).

Örnek çalışma sahamız olan Isparta Orman İşletme Müdürlüğü Keçiborlu Orman İşletme Şefliği sınırlarında bulunan Güneykent Bal Üretim ormanı 182, 184, 185 ve 186 nolu bölmelerdeki BKBt (bozuk baltalık) ve OT (orman toprăğ) meşçere tipi olan 138,5 ha sahada yalancı akasya, yabani elma, yabani erik, badem, iğde, alıç, lavanta vb. arıcılık açısından önemli türlerle dikimler ve ekimler yapılmış sahadaki doğal olarak bulunan bozuk koru, bozuk meşe ve kekik, kırmızı üçgül ve geven gibi türler yoğun bir şekilde bulunmakta olup, bu bitkilerle birlikte sahadaki her türlü flora etrafi tel ihata ile çevrilerek koruma altına alınmıştır.

\subsection{Topografik özellikleri}

Çalışma alanı Isparta İli Gönen İlçesi Güneykent Beldesi sınırları içerisinde Keçiborlu Orman İşletme Şefliği Güneykent Bal Üretim ormanındadır. Çalışma alanı arazisinin Güneykent Beldesine en yakın yeri kuş uçuşu $2000 \mathrm{~m}$, en uzak yeri $4000 \mathrm{~m}$ mesafededir. Çalışma alanı \% 
15-40 eğim grubundadır. Güneykent, doğusunda İğdecik köyü, Gönen İlçesi, kuzeyinde Uluborlu İlçesi, İleydağı köyü, Özbahçe köyü, batısında Keçiborlu İlçesi, güneyinde Kılıç köyü ve Senir Beldesi ile bitişiktir. Güneykent, Kapı dağının uzantısı olan Tepelci, Erenler Dağı ve Demirli dağlarının ortasında Güney'e bakan bir yamaçta kurulmuştur. Güneykent her türlü hayvancillğ 1 yapmaya elverişlidir. Arazilerin engebeli olması erozyonu hızlandırmakta, verimin düşmesine neden olmaktadır. Kasabanın bulunduğu yerin rakımı 1250 dir. Güney kısmında bulunan ovası Burdur gölüne doğru uzanmaktadır (Anonim, 2018).

\section{3. İklim}

Çalışma alanı Akdeniz Bölgesinde bulunmasına rağmen İç Ege ve İç Anadolu Bölgesi iklimleride etkisini gösterir. Yazları serin, kışları da çok soğuk geçer. En düşük sıcaklık -1,8 OC ile Ocak ayında tespit edilmiştir. En yüksek sıcaklık 30,5 OC ile Ağustos ayında tespit edilmiştir. En az yağış Ağustos ayında görülmekte, daha çok yağgş ise Aralık, Ocak ve Şubat aylarında görülmektedir. Günlük en çok yağış miktarı 84.3 ve $76.9 \mathrm{~mm}$. ile Aralık ve Ocak aylarında, en az ise $10.7 \mathrm{~mm}$. ile Ağustos ayında görülmektedir. En yüksek buharlaşma Temmuz ve Ağustos aylarındadır. Yıl içerisinde yağışsız ay bulunmamaktadır (Anonim, 2018).

\subsection{Toprak yapısı}

Çalışma alanında ana kaya esas olarak sert kalker olup hafif dağlık bölgelerde granit, kil taşı, kum taşı, çeşitli metamorfikler, kristal kayalar, fliş ve kireç taşıdır (Anonim, 2015). Bu ana kayaların parçalanması ile kumlu ve az oranda killi topraklar oluşmuştur. Düzlük yerlerde toprak derin olup, sırtlara doğru yüzeysel denilecek kadar azalmaktadır.
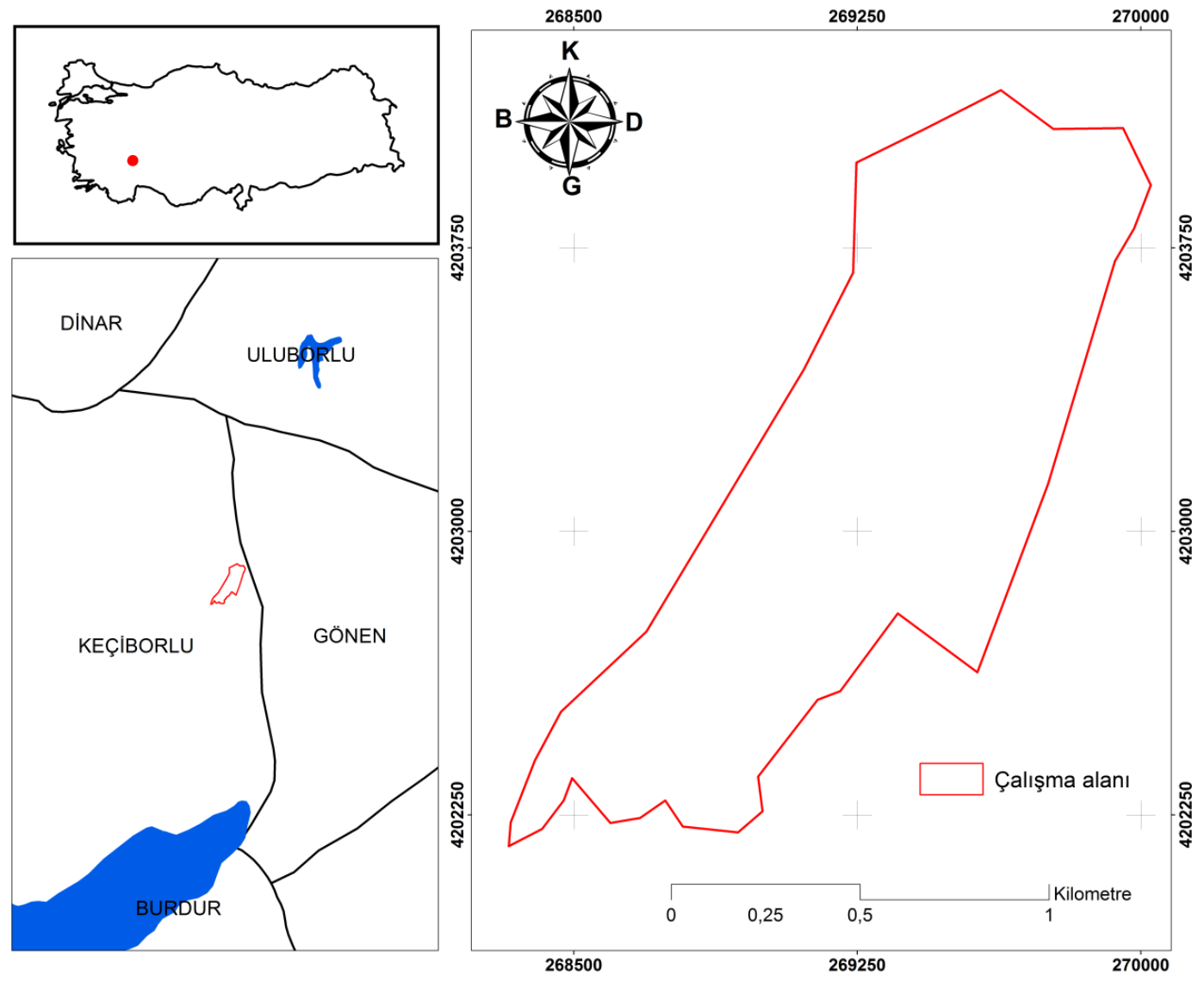

Şekil 1. Çalışma alanı mevki haritası ve örnek alınan noktaları 


\section{Yöntem}

Çalışma 2015-2016 yılları arasındaki vejetasyon dönemlerinde (Mart- Eylül) yürütülmüştür. Güneykent Bal Üretim Ormanında yıl içerisinde nektar akımı dönemini uzatmak amacıyla bitkilerin çiçeklenme dönemi dikkate alınarak yörenin orjinine uygun türlerle dikimler yapılmıştır. Tohum ve/veya fidan kullanılırken yetişme ortamına uygun türler ve orijininden olmalarına dikkat edilmiştir. Bal ormanındaki türlerin çiçek tutmaları büyük önem arz ettiğinden, dikimlerdeki aralık mesafesine dikkat edilmiştir.

Çalışma alanına iki hafta ara ile gidilerek flora taraması yapılmıştır. Tibbi aromatik öneme sahip çiçekli bitkiler gözlemlenerek bu bitkileri arıların ziyaret edip etmediği tespit edilmiştir. Arılar tarafından ziyaret edilen bitkilerden örnekler toplanmış, bunlar preslere konularak herbaryuma getirilmiştir. Ayrıca arazide toplanan bitki türlerinin dijital fotoğrafları çekilmiştir.

Örnekler alınırken, bitkilerin teşhisinde özellikle gerekli olan çiçek, yaprak, gövde ve kök gibi organlarının tam olarak alınmasına dikkat edilmiş ve her örneğe bir numara verilmiştir. Bitkilerin toplandığ 1 alanlar ve toplanma zamanları not edilmiştir. Bitkiler farklı zamanlarda çiçeklendiği için aynı alanlara vejetasyon dönemi boyunca çeşitli zamanlarda gidilerek değişik zamanlarda çiçeklenen bitkilerden de örnekler alınması sağlanmıştır. Herbaryuma getirilen bitkilerin tür teşhisleri yapıldıktan sonra, bunlardan hangilerinin tıbbi-aromatik bitki oldukları belirlenmiştir. Bu bitki taksonlarından arıcılık için önemli olanları, çiçeklenme zamanları ve endemiklik durumu ile birlikte alfabetik olarak listelenmiştir

\section{Araştırma bulguları}

Bal Ormanı olarak tesis edilen çalışma alanında 23 familyaya ait, tıbbi ve aromatik özelliğe sahip olan 53 adet bitki taksonu tespit edilmiştir (Çizelge 3.1). Bu bitki taksonlarından 17 adedi dikim ve ekim yoluyla elde edilmiştir (Çizelge $3.1)$.

Çizelge 3.1. Çalışma alanı olan Güneykent bal üretim ormanında bulunan arıcılık için önemli tıbbi-aromatik bitkiler ve bazı önemli özellikleri

\begin{tabular}{|c|c|c|c|}
\hline Familya & $\begin{array}{l}\text { Türün bilimsel adı (Latince } \\
\text { adı) }\end{array}$ & Türkçe Adı & $\begin{array}{l}\text { Çiçeklenme } \\
\text { Zamanı }\end{array}$ \\
\hline Apiaceae & Ammi visnaga $\mathrm{L}$. (Lam.) & Diş otu & Mayıs-Temmuz \\
\hline Apiaceae & $\begin{array}{l}\text { Eryngium campestre L. var. } \\
\text { virens Link. }\end{array}$ & $\begin{array}{l}\text { Boğa Dikeni } \\
\text { Şeker Dikeni }\end{array}$ & Temmuz-Eylül \\
\hline Asteraceae & Achillea teretifolia Willd. & Civanperçemi & Haziran-Temmuz \\
\hline Asteraceae & Cichorium intybus L. & Hindiba & Nisan-Ağustos \\
\hline Asteraceae & Inula anatolica Boiss. & Andız Otu & Haziran-Ağustos \\
\hline Asteraceae & $\begin{array}{l}\text { Onopordum carduchorum } \\
\text { Bornm. \& Beauverd. }\end{array}$ & Eşek Dikeni & Haziran-Temmuz \\
\hline Asteraceae & $\begin{array}{l}\text { Xanthium strumarium } \\
\text { subsp. strumarium }\end{array}$ & Butrak & Temmuz-Ekim \\
\hline Boraginaceae & Echium italicum $\mathrm{L}$. & Engerek Otu & Mayıs-Temmuz \\
\hline Boraginaceae & Onosma oreodoxum Boiss. & Emzik Otu & May1s-Haziran \\
\hline Boraginaceae & Phacelia tanacetifolia Benth. & Ar1 Otu & Haziran-Temmuz \\
\hline Brassicaceae & $\begin{array}{l}\text { Alyssum dasycarpum Steph ex } \\
\text { Willd var. dasycarpum }\end{array}$ & Kuduz Otu & Mart- Mayis \\
\hline Brassicaceae & $\begin{array}{lll}\text { Capsella } & \text { bursa-pastoris } & \mathrm{L} . \\
\text { Medik. } & & \end{array}$ & Çoban Çantası & Nisan-Ağustos \\
\hline
\end{tabular}


Bilge International Journal of Science and Technology Research 2019, 3(2): 213-222

\begin{tabular}{|c|c|c|c|}
\hline Brassicaceae & $\begin{array}{l}\text { Fibigia clypata (L.) Medik. } \\
\text { var. eriocarpa (DC.) Post. }\end{array}$ & Sikkeotu & Nisan-Mayıs \\
\hline Colchicaceae & Colchicum variegatum $\mathrm{L}$. & Güz çiğdemi & Ekim-Kasım \\
\hline Cupressaceae & $\begin{array}{l}\text { Juniperus excelsa M.Bieb. } \\
\text { excelsa }\end{array}$ & Boylu Ardıç & - \\
\hline Cupressaceae & $\begin{array}{l}\text { Juniperus oxycedrus L. subsp. } \\
\text { oxycedrus }\end{array}$ & Katran Ardicı & - \\
\hline Euphorbiaceae & Euphorbia kotschyana Fenzl. & Sütleğen & Mayıs-Temmuz \\
\hline Elaeagnaceae & Elaeagnus angustifolia L. & İğde & Nisan-Haziran \\
\hline Fabaceae & $\begin{array}{l}\text { Astragalus angustifolius Lam. } \\
\text { subsp. longidens Hub.-Mor. } \\
\text { \& Matthews. }\end{array}$ & Geven & Haziran-Temmuz \\
\hline Fabaceae & $\begin{array}{l}\text { Astragalus } \quad \text { gymnolobus } \\
\text { Fischer. }\end{array}$ & Geven & May1s-Haziran \\
\hline Fabaceae & Robinia pseudoacacia $\mathrm{L}$. & Yalancı Akasya & Mayıs-Haziran \\
\hline Fabaceae & $\begin{array}{l}\begin{array}{l}\text { Trifolium arvense L. var. } \\
\text { arvense }\end{array} \\
\end{array}$ & Yonca & Nisan-Temmuz \\
\hline Fabaceae & $\begin{array}{l}\text { Trifolium pratense L. var. } \\
\text { pratense }\end{array}$ & Yonca & Nisan-Ağustos \\
\hline Fagaceae & Quercus coccifera $\mathrm{L}$. & Kermes Meşesi & Ağustos \\
\hline Fagaceae & Quercus robur L.subsp. robur & Saplı Meşe & Ağustos-Eylül \\
\hline Juglandaceae & Juglans regia $\mathrm{L}$. & Adi Ceviz & May1s \\
\hline Lamiaceae & $\begin{array}{l}\text { Lavandula } \mathrm{x} \\
\text { Emerice } \mathrm{x} \text { Loisel. }\end{array}$ & Lavanta & Temmuz-Ağustos \\
\hline Lamiaceae & Origanum onites $\mathrm{L}$. & Bilyalı kekik & Mayıs-Temmuz \\
\hline Lamiaceae & Phlomis armenica Willd. & Çoban çırası & Haziran-Ağustos \\
\hline Lamiaceae & $\begin{array}{l}\text { Phlomis grandiflora H. S. } \\
\text { Thompson var. grandiflora }\end{array}$ & Çalba & Mayı-Temmuz \\
\hline Lamiaceae & Salvia tomentosa Miller & $\begin{array}{l}\text { Büyük Çiçekli } \\
\text { Ada Çayı }\end{array}$ & Nisan-Haziran \\
\hline Lamiaceae & $\begin{array}{l}\text { Stachys lavandulifolia Vahl. } \\
\text { var. lavandulifolia }\end{array}$ & Dağ Çayı & Mayıs-Temmuz \\
\hline Lamiaceae & Teucrium polium L. & Kisa Mahmut & Hazi,ran-Ağustos \\
\hline Lamiaceae & $\begin{array}{l}\text { Thymus zygioides Griseb. var. } \\
\text { lycaonicus (Celak.) Ronniger }\end{array}$ & Kekik & Mayıs-Haziran \\
\hline Moraceae & Morus alba $\mathrm{L}$. & Ak Dut & Mayıs \\
\hline Oleaceae & $\begin{array}{l}\text { Fraxinus ornus L. subsp. } \\
\text { cilicica (Lingelsh.) Yalt. }\end{array}$ & Çiçekli Dişbudak & Nisan-Mayıs \\
\hline Papaveraceae & Glaucium leiocarpum Boiss. & Gülfatma & Mayıs-Haziran \\
\hline Pinaceae & Pinus brutia Ten. var. brutia & Kızılçam & Haziran \\
\hline Pinaceae & $\begin{array}{l}\text { Pinus nigra J.F. Arnold. } \\
\text { subsp. nigra var. caramanica } \\
\text { (Loudon) Rehder }\end{array}$ & Karaçam & - \\
\hline Platanaceae & Platanus orientalis $\mathrm{L}$. & Çınar & Mart-May1s \\
\hline Plantaginaceae & $\begin{array}{l}\text { Digitalis ferruginea L. subsp. } \\
\text { ferruginea }\end{array}$ & Yüksük Otu & Mayıs-Temmuz \\
\hline Plumbaginaceae & $\begin{array}{l}\text { Acantholimon acerosum } \\
\text { (Willd.) Boiss. var. acerosum }\end{array}$ & Çoban Yastığ1 & Haziran-Temmuz \\
\hline Rhamnaceae & $\begin{array}{l}\text { Rhamnus rhodopeus } \\
\text { Velenovsky subsp. anatolicus } \\
\text { (Grub.) Browicz \& Ziellinski }\end{array}$ & Cehri & Mayıs \\
\hline
\end{tabular}


Bilge International Journal of Science and Technology Research 2019, 3(2): 213-222

\begin{tabular}{|c|c|c|c|}
\hline Rosaceae & Amygdalus communis L. & Badem & Mart-Nisan \\
\hline Rosaceae & Armeniaca vulgaris Lam. & Yabani Kayısı & Nisan-Mayıs \\
\hline Rosaceae & $\begin{array}{l}\text { Cotoneaster } \quad \text { nummularia } \\
\text { Fisch. \& Mey. }\end{array}$ & Tavşan Elması & Nisan-May1s \\
\hline Rosaceae & $\begin{array}{l}\text { Crataegus monogyna Jacq. } \\
\text { subsp. azarelle (Gris.) Franco }\end{array}$ & Kırmızı Alıç & Nisan-Haziran \\
\hline Rosaceae & $\begin{array}{l}\text { Crataegus orientalis Pallas \& } \\
\text { Bieb. var. orientalis }\end{array}$ & Alıç & Mayıs-Temmuz \\
\hline Rosaceae & $\begin{array}{l}\text { Malus sylvestris Miller subsp. } \\
\text { orientalis (A. Uglitzkich) } \\
\text { Browicz }\end{array}$ & Yabani Elma & Nisan \\
\hline Rosaceae & $\begin{array}{l}\text { Prunus spinosa L. subsp. } \\
\text { dasyphylla (Schur) Domin }\end{array}$ & Yabani Erik & Nisan-Mayis \\
\hline Rosaceae & $\begin{array}{l}\text { Pyrus elaeagnifolia Pallas } \\
\text { subsp. elaeagnifolia }\end{array}$ & Ahlat & Nisan-Mayıs \\
\hline Rosaceae & Rosa canina $\mathrm{L}$ & Kuşburnu & Mayıs-Temmuz \\
\hline Rubiaceae & $\begin{array}{l}\text { Galium verum L. subsp. } \\
\text { verum }\end{array}$ & Yoğurt otu & Mayıs-Temmuz \\
\hline
\end{tabular}

Çizelge 3. 2. Çalışma alanı olan Güneykent bal üretim ormanında dikim ve ekim yoluyla elde edilen arıcılık için önemli tıbbi-aromatik bitkiler

\begin{tabular}{|c|c|c|c|c|}
\hline Familya & Türün bilimsel adı (Latince adı) & Türkçe Adı & $\begin{array}{l}\text { Dikim } \\
\text { Adet }\end{array}$ & $\begin{array}{l}\text { Ekim } \\
\text { Miktarı } \\
\text { (kg) }\end{array}$ \\
\hline Cupressaceae & $\begin{array}{llll}\begin{array}{l}\text { Juniperus } \\
\text { oxycedrus }\end{array} & \text { oxycedrus } & \text { L. } & \text { subsp. } \\
\end{array}$ & Katran Ardicı & 500 & \\
\hline Elaeagnaceae & Elaeagnus angustifolia $\mathrm{L}$. & İğde & 500 & \\
\hline Fagaceae & Quercus robur L. subsp. robur & Sapl1 Meşe & 1750 & \\
\hline Fabaceae & Robinia pseudoacacia $\mathrm{L}$. & Yalancı Akasya & 19000 & \\
\hline Boraginaceae & Phacelia tanacetifolia Benth. & Ar1 Otu & - & 88 \\
\hline Juglandaceae & Juglans regia $\mathrm{L}$. & Adi Ceviz & 750 & \\
\hline Lamiaceae & $\begin{array}{l}\text { Lavandula } x \text { intermedia Emerice } \mathrm{x} \\
\text { Loisel. }\end{array}$ & Lavanta & 6500 & \\
\hline Moraceae & Morus alba $\mathrm{L}$. & Ak Dut & 500 & \\
\hline Rosaceae & $\begin{array}{l}\text { Pyrus elaeagnifolia Pallas subsp. } \\
\text { elaeagnifolia }\end{array}$ & Ahlat & 500 & \\
\hline Rosaceae & Armeniaca vulgaris Lam. & Yabani Kayısı & 1000 & \\
\hline Rosaceae & Amygdalus communis L. & Badem & 1500 & \\
\hline Rosaceae & $\begin{array}{l}\text { Malus sylvestris Miller subsp. } \\
\text { orientalis (A. Uglitzkich) Browicz }\end{array}$ & Yabani Elma & 500 & \\
\hline Rosaceae & $\begin{array}{l}\text { Prunus spinosa L. subsp. dasyphylla } \\
\text { (Schur) Domin }\end{array}$ & Yabani Erik & 500 & \\
\hline Rosaceae & Crataegus orientalis M.Bieb. & Alıç & 500 & \\
\hline Rosaceae & $\begin{array}{l}\text { Crataegus orientalis Pallas \& Bieb. } \\
\text { var. orientalis }\end{array}$ & Kırmızı Alıç & 500 & \\
\hline Oleaceae & $\begin{array}{l}\text { Fraxinus ornus L. subsp. cilicica } \\
\text { (Lingelsh.) Yalt. }\end{array}$ & Çiçekli Dişbudak & 500 & \\
\hline \multirow[t]{2}{*}{ Platanaceae } & Platanus orientalis $\mathrm{L}$ & Çınar & 500 & \\
\hline & TOPLAM & & 35500 & 88 \\
\hline
\end{tabular}


Çalıșma alanına dikilen fidanlar $3 \times 3 \mathrm{~m}$ aralıklarla bulunan teraslara yapraklı türler $3 \times 3 \mathrm{~m}$, iğne yapraklı türler $3 \times 2 \mathrm{~m}$, otsu türler $1 \times 1 \mathrm{~m}$ mesafelerle dikildiklerinden, sahadaki başarı durumlarının belirlenmesi de belli bir sistematik esasa göre yapılan fidan sayımlarıyla ortaya konulmuştur. Çalışma alanının alt tabanında durularak (tesis alanı önümüze gelecek şekilde) sol kenarından başlayan 10'uncu terasa gidilerek (çıkılarak) 30 fídana tekabül eden yerdeki fidanların sağlıklı ve iyi gelişenleri sayılmıştır.
Aynı teras veya eş yükselti eğrisinde yürünerek başlangıçtan itibaren her 100 metrede aynı şekilde 30 fidana tekabül eden yerlerdeki fidanların sağlıklı ve iyi gelişenleri sayılmıştır. Bulunan değerler 10. terasa ait yatay sütuna yazılmıştır. Örnek çalışma alanımızın sonuna gelindiğinde 20 . terasa gidilerek (çıkılarak) aynı işlemler örnek çalışma alanımız tamamen sayılıncaya kadar devam etmiştir. Çalışma alanı olan Güneykent Bal Üretim Ormanında dikilen başarı oranını gösterir cetvel Çizelge 3.3.'de gösterilmiştir.

Çizelge 3.3. Çalışma alanı olan Güneykent bal üretim ormanında dikilen fidanların başarı oranını gösterir cetvel

\begin{tabular}{|l|l|l|l|l|l|l|}
\hline Teras No & $\begin{array}{l}\mathbf{0} \\
\text { Başlangıç }\end{array}$ & $\begin{array}{l}\mathbf{1 0 0} \\
\text { Metre }\end{array}$ & $\begin{array}{l}\mathbf{2 0 0} \\
\text { Metre }\end{array}$ & $\begin{array}{l}\mathbf{3 0 0} \\
\text { Metre }\end{array}$ & $\begin{array}{l}\mathbf{4 0 0} \\
\text { Metre }\end{array}$ & $\begin{array}{l}\mathbf{5 0 0} \\
\text { Metre }\end{array}$ \\
\hline 10 & 25 & 22 & 30 & 23 & 29 & 22 \\
\hline 20 & 23 & 30 & 26 & 28 & 25 & 24 \\
\hline 30 & 30 & 20 & 28 & 29 & 24 & 27 \\
\hline 40 & 29 & 29 & 28 & 24 & 26 & 22 \\
\hline 50 & 29 & 30 & 18 & 16 & 19 & 22 \\
\hline 60 & 25 & 22 & 30 & 23 & 29 & \\
\hline 70 & 23 & 30 & 26 & 28 & 25 & \\
\hline 80 & 30 & 20 & 28 & 29 & 23 & \\
\hline 90 & 29 & 29 & 28 & 23 & 26 & \\
\hline 100 & 30 & 22 & 22 & 24 & 23 & \\
\hline 110 & 30 & 18 & 16 & 17 & 26 & \\
\hline 120 & 29 & 15 & 24 & 14 & 26 & \\
\hline 130 & 29 & 29 & 27 & 13 & 24 & \\
\hline 140 & 30 & 14 & 18 & 25 & 26 & \\
\hline 150 & 29 & 24 & 23 & 22 & 27 & \\
\hline 160 & 30 & 26 & 22 & 22 & 26 & \\
\hline TOPLAM & A1=450 & A2=380 & A3=394 & A4=360 & A5=404 & A6=117 \\
\hline
\end{tabular}

$\mathbf{A}=$ Normal gelişme gösteren fidanların toplamıdır, $\mathrm{B}=$ Bulunması gereken 30 fidanın, ölçüm yapılan nokta adedinin çarpımı ile bulunan sayıdır.

Fidan Tutma Başarı Oranı Hesaplaması, gelişme gösteren fidanların toplamının, bulunması gereken 30 fidanın, ölçüm yapılan nokta adetinin çarpımı ile bulunan sayıya bölünmesi ile hesaplanmıştır.

$$
(\mathrm{A} 1+\mathrm{A} 2+\mathrm{A} 3+\mathrm{A} 4+\mathrm{A} 5+\mathrm{A} 6) / \mathrm{B}=(450+380+394+360+404+117) /(85 * 30)=2105 / 2550=\% 83
$$

\section{Tartışma ve Sonuç}

Tibbi ve aromatik bitkiler yönünden zengin bir familya olan Rosaceae, Fabaceae ve Lamiaceae familyasının arıcılık açısından da oldukça önemli olduğu belirlenmiştir. Bununla birlikte Asteraceae familyası da arıcılık için önemli olan diğer familya olarak saptanmıştır. Bal ormanı tesisinde kullanılan yapraklı ağaç türleri toprağın derinliklerinden beslendiği için kısa dönemli kuralıklarda bile nektar verimine devam ederken, otsu türlerin kısa süreli kuraklığa dayanamayıp çok çabuk kuruması sebebi ile arıcılık açısından istenen verimi sağlayamadığı görülmüsstür. Güneykent Bal üretim ormanı örnek sahamızda tam alanda toprak işleme çalışması yapılmadan, otsu bitkileride sahada tutarak, farklı rakım ve farklı türlerin karışımının aynı sahada kullanılmasıyla yapılan dikimlerin çiçeklenme ve nektar verimi açısından çok zengin olduğu tespit 
edilmiştir. Örnek sahamızda yapılan dikimlerin fidan sayımlarına göre başarı oranı $\% 83$ dür.

Fidanların kuruma sebeplerinden bazılarının orman yaban hayatında bulunan kemirgen bir hayvanın (tavşan) dikilen yapraklı türlere, topraktan $10-15 \mathrm{~cm}$ yukarısından kemirmek suretiyle zarar vermesi ve yaban domuzunun vermiş olduğu zararlar olarak tespit edilmiştir. Göçebe arıcılığın yaygın olarak yapıldığ 1 yörede arı kovanlarının bu bitkilerin yoğun olarak bulunduğu sahalara taşınması arıcılık açısından büyük avantajlar sağlayacaktır. Zaman olarak ise arı kovanlarının, Mart sonu ve Nisan başlarında çiçeklenmenin yeni başladığı alçak rakımlı kesimlere, Mayıs ve Haziran aylarında ise çiçeklenmenin daha geç başladığı yüksek rakımlı dağlı kesimlere konulması uygun olacaktır.

Çalışmanın sonuçlarına göre; bölgede rakımın düşük olduğu kesimlerde geniş bir şekilde yayılış gösteren bilyalı kekik bitkisi (Origanum onites)'nin arılar tarafından yoğun olarak ziyaret edildiği belirlenmiştir. Ayrıca alıç türleri (Crataegus spp.), Çalba (Phlomis grandiflora), ada çayı türleri (Salvia spp.), arılar tarafından sık ziyaret edilen diğer bitkilerdir. Rakımın yüksek olduğu kesimlerde ise, çiçekli dişbudak (Fraxinus ornus subsp. cilicica), ahlat (Pyrus elaeagnifolia subsp. elaeagnifolia), kuşburnu (Rosa canina), geven türleri (Astragalus spp.), çoban çırası (Phlomis armeniaca) Lavanta (Lavandula Angustifolia) ve üçgül türleri (Trifolium spp.) arılar tarafından sık ziyaret edilen bitki taksonları olarak öne çıkmaktadır.

Tüzün vd., (2013), yapmış oldukları çalışma da arıların doğal ve tarımsal ekosisteme olan katkılarının önemini vurgulamıştır. Bu bağlamda, yapmış olduğumuz çalışma ile doğal ekosistem içinde tespit ettiğimiz ve arazilerde ekim ve dikim yoluyla kullandığımız türler ve alana getirilen arı kovanları sayesinde ekolojik dengenin korunması sağlanmaya çalışılmıştır.

Ceyhan ve Emir (2013), tarafindan Tarım Bilgi Sistemi ile entegre kovan takip sistemi kurularak, konaklama yerlerinin optimum kullanımı için arı konaklama yerleri ve kapasiteleri belirlenmesi gerektiği vurgulanmıştır. Tesis edilen Güneykent bal üretim ormanı, arıcılar için kapasitesi belli arı konaklama yerlerinden biri olmuştur.

Cengiz, (2018), Narman (Erzurum) ilçesinin çok sayıda ballı bitki türü olan geniş doğal meralara ve bölgedeki meralarda kimyasal gübreleme veya yabancı ot ve zararlı kontrolü için diğer kimyasal maddeler kullanılmadığından organik bal üretimi için önemli bir potansiyele sahip olduğunu tespit etmiştir. Bölgede üretilen yüksek kaliteli organik bal, tüm ülke genelinde talep gördüğü ve bal üreticileri, bal üretiminden önemli bir gelir elde ettiklerini vurgulamıştır. Yapılan bu çalışma ile Güneykent bal üretim ormanı yüksek kaliteli organik bal elde etmek potansiyeline kavuşturulmuştur.

Demir, (2014), yapmış olduğu çalışma da Kars İlindeki arıcılık üretiminin tamamen doğal koşullara bağlı olarak yapılması halinde, ürün niteliği tatmin edici düzeyde olabilmesine rağmen, ürün niceliği ve kovan başına verim yıllara göre değişmekle beraber düşük düzeyde olduğunu belirlemiştir. $\mathrm{Bu}$ çalışma, arıcılık üretiminin doğal koşullara bağlı olarak yapılması halinde de ürün niceliği ve kovan başına verimin yıllara göre arttırmak için çözüm niteliği taşımaktadır.

Sonuç olarak, yörede arıcılığın geliştirilmesi için halk tıbbi aromatik bitkiler ve arıcılık konularında eğitilmelidir. Bununla birlikte arıcılık için önemli olan tıbbi ve aromatik bitkilerinin çiçeklenme zamanları dikkate alınmalı ve arıcılık için önemli bir tehdit durumunda olan otlatma buna göre planlanmalıdır. Bunlar uygulamaya konulduğu takdirde yöre arıcılığına büyük katkı sağlayacaktır.

\section{Teşekkür}

Çalışmamızı maddi olarak destekleyen Süleyman Demirel Üniversitesi Bilimsel Araştırma Projeleri Yönetim Birimi Başkanlığı'na teşekkür ederiz (Proje No:4335-YL1-15).

\section{Kaynaklar}

Anonim, (2015), http://www.balormanı.gov.tr, Erişim tarihi: 28.02.2015.

Anonim, (2017), https://www.ogm.gov.tr, Erişim tarihi: 24.03.2017.

Anonim,

http://www.ispartakulturturizm.gov.tr, Erişim tarihi: 25.09.2018.

Demir, M. (2014). Kars İlinin Arıcıllk Potansiyeli ve Değerlendirme Durumu. Doğu Coğrafya Dergisi. Cilt 19, Sayı 32, sayfa 209-230. 
Cengiz, M.M., (2018). Arıcıllk ve Organik Bal Üretimi için Narman (Erzurum, Türkiye) Doğal Meralarında Ballı Bitki Potansiyeli, GUFBED 8(2), (2018), 358-364.

Ceyhan, V., Emir, M., (2013). Türkiye'de Arıcıların Göç Yolları, Arı Ürünleri Verimliliği ve Fiyatları. 12. Ulusal Tarım Ekonomisi Kongresi 2016, Cilt: 3, 25-27 Mayıs, Isparta.

Günaydın G., (2007). Avrupa Birliği Kırsal Kalkınma Politika Transferi Analizi: Türkiye'de Kalkınma Planlarının Ulusal Kırsal Kalkınma Stratejisi' Tarım ve Mühendislik, TMMOB Ziraat Mühendisleri Odas1 Yayım Organ1, Say1:80/2007, ISSN-1300-0071, Ankara. s. 25.

Özcan, F. (2011). Göller Bölgesi'nde Arı Ürünlerinin Pazar ve Pazarlama Sorunları, uygulanabilecek pazarlama stratejileri. Yüksek Lisans Tezi, Süleyman Demirel Üniversitesi Sosyal Bilimler Enstitüsü.

Parlakay, O., Yılmaz, H., Yaşar, B., Seçer, A., Bahadır, B., (2008). Türkiye'de Arıcılık Faaliyetinin Mevcut Durumu ve Trend Analizi Yöntemiyle Geleceğe Yönelik Beklentiler, Uludağ Üniversitesi Ziraat Fakültesi Dergisi, Cilt 22, Say1 2, 17-24.

TUIK, (2015). Türkiye İstatistik Kurumu, Tarım İstatistik Raporu, Ankara.

Tüzün, A., Bilgili, G., (2013). Tarımsal Ekosistemde Arıların Önemi. Biyoloji Bilimleri Araştırma Dergisi 6 (2): 91-95, 2013 ISSN: 1308-3961, E-ISSN: 13080261, Ankara.

Vural, H. (2008). Türkiye'de Bal Üretimi ve Pazarlaması. 1.Uluslararası Muğla Arıcılık ve Çam Balı Kongresi. 25- 27 Kasım, Muğla, s.223-232.

Yaşar, N., Karataş, Ü., (2012). Avrupa Birliği Ülkeleri ve Türkiye'de Arıcılık, Arıcılık Araştırma Dergisi Yı1:4 Sayı:7, Ordu. 